\title{
Analisando a retomada anafórica do objeto direto em português falado
}

Analysing anaphoric direct object in spoken portuguese

\author{
Gabriel de Ávila Othero* \\ Ana Carolina Spinelli ${ }^{*+}$
}

\begin{abstract}
RESUMO
Em português brasileiro (PB), duas diferentes estratégias para a retomada anafórica de objetos são conhecidas: por um lado, temos a preferência por pronomes clíticos na retomada de $1^{\mathrm{a}} \mathrm{e}$ $2^{\text {a }}$ pessoas; por outro, na retomada anafórica de $3^{\text {a }}$ pessoa, a queda dos clíticos - em seu lugar, encontramos pronomes plenos ou uma categoria vazia na posição de objeto. Aqui, buscamos explicar qual motivação gramatical influencia a retomada anafórica que condiciona o uso de pronomes ou categorias vazias na retomada anafórica de objeto. Para isso, comparamos duas hipóteses conhecidas na literatura sobre o assunto. A primeira hipótese, adotada, por exemplo, por Cyrino (1993, 1994/1997), aponta o traço de animacidade e sua combinação com o traço de especificidade como fator condicionador da escolha entre o uso de pronome ou objeto nulo (ON). Por outro lado, há a hipótese do gênero semântico do referente (CREUS; MENUZZI, 2004): o gênero semântico seria o traço relevante na distribuição entre pronomes e ONs em PB. Avaliamos aqui qual dessas duas hipóteses tem maior poder explicativo no condicionamento dessas duas estratégias de retomada anafórica em PB. Para isso, pesquisamos ocorrências de retomadas anafóricas em função de objeto em um corpus composto por 19 entrevistas do VARSUL. Verificamos a manutenção dos clíticos de primeira e segunda pessoas e a queda do clítico de terceira pessoa, que dá lugar, principalmente, ao ON. A hipótese que explica o condicionamento entre pronome e $\mathrm{ON}$ de forma mais acurada parece ser a do gênero semântico, já que, com ela, temos resultados mais polarizados. Além disso, essa hipótese é mais econômica do que a hipótese dos traços de animacidade e especificidade do referente.
\end{abstract}

Palavras-chave: língua falada; português brasileiro; objeto nulo; retomada anafórica; VARSUL.

\footnotetext{
* Professor Adjunto na Universidade Federal do Rio Grande do Sul - UFRGS gabriel.othero@ufrgs.br

* Mestranda na Universidade Federal do Rio Grande do Sul - UFRGS ana.carolina.spinelli@gmail.com
} 
G. DE A.

OTHERO \& A.

C. SPINELli

Analisando

a retomada

anafórica do

objeto direto em português falado

\begin{abstract}
In Brazilian Portuguese (BP), two different strategies for the anaphoric retrieval of objects are known: on the one hand, we have the preference for clitic pronouns in the anaphor for $1^{\text {st }}$ and $2^{\text {nd }}$ person. On the other hand, in the anaphoric recovery of the $3^{\text {rd }}$ person, we find full pronouns or an empty category in the object position. In this paper we seek to explain the grammatical motivation influencing anaphoric resumption involving the use of pronouns or empty categories in anaphoric verbal objects. We compare two hypotheses known in the literature on the subject. The first hypothesis, adopted, for example, by Cyrino (1993, 1994/1997), points out the trace of animacity and its combination with the trait of specificity as a conditioning factor regulating the use of a pronoun or a null object. On the other hand, there is the hypothesis of the semantic gender of the referent (cf. CREUS; MENUZZI, 2004): the semantic gender would be the relevant trait in the distribution between pronouns and null objects in BP. Here we evaluate which of these two hypotheses has greater explanatory power in the conditioning of these two strategies of anaphoric resumption in BP. For this, we investigated occurrences of anaphoric resumptions of verbal objects in a corpus composed of 19 interviews of VARSUL. We verified the maintenance of the $1^{\text {st }}$ and $2^{\text {nd }}$ person clitics and the decay of the $3^{\text {rd }}$ person clitic. The hypothesis that explains the conditioning between pronoun and null object more accurately seems to be that of the semantic gender: when we assume it, we have more polarized results and, moreover, this hypothesis is more economical than the hypothesis of the characteristics of the referent and specificity.
\end{abstract}

Keywords: spoken discourse; Brazilian Portuguese; Null object; anaphor; VARSUL. 


\section{Introdução $0^{1}$}

processo de queda do clítico acusativo de terceira pessoa no português brasileiro (PB) tem dado lugar a duas diferentes estratégias de retomada anafórica: o uso de pronome pleno e de objeto nulo (ON), como atestam vários trabalhos em $\mathrm{PB}$, seja com base em dados de língua escrita (OMENA, 1978; DUARTE, 1989; CYRINO, 1994/1997; OLIVEIRA 2007), língua falada (MONTEIRO, 1994; PINTO; COELHO, 2016) ou de aquisição da linguagem e linguagem infantil (CASAGRANDE 2007, 2012; AYRES, 2016; AYRES; OTHERO, 2016). Nosso trabalho se concentra no estudo da retomada anafórica do objeto direto em português falado e consiste na análise da amostra de Porto Alegre do corpus de fala do projeto VARSUL (um projeto que coleta dados de fala da região sul do Brasil, cf. COLLISCHOM; MONARETTO, 2012; BISOL; MONARETTO, 2016). Nosso objetivo central é pesquisar a retomada anafórica de objeto direto na variedade falada da língua, considerando a ocorrência de pronomes e ONs, contribuindo para a compreensão dos fatores relevantes na escolha entre uma ou outra estratégia, tais como encontramos nos exemplos (1) e (2), abaixo:

1 Agradecemos pela leitura e pelos comentários dos colegas Marcos Goldnadel e Mônica Rigo Ayres. Também agradecemos pelo parecer detalhado que um dos pareceristas anônimos elaborou. Todas as inconsistências encontradas no texto são de nossa inteira responsabilidade. 
G. DE A. Othero \& A.

C. SPinelli Analisando a retomada anafórica do objeto direto em português falado

1. Eu vou tirar a mesa, desmontar [a mesa da sala $]_{\mathrm{i}}$ e botar $\varnothing_{\mathrm{i}}$ no chão. (RS POA $01 \mathrm{MB}^{2}$ )

2. [Meu filho $]_{i}$, ele fica o dia todo lá, ele vai às oito da manhã e cinco e vinte a gente vai buscar ele. (RS POA $27 \mathrm{M}$ )

Acreditamos que o uso de objeto nulo ou de pronome na retomada anafórica de terceira pessoa seja condicionado pelos traços discursivos e gramaticais do seu referente. Estudos pioneiros, como Duarte (1993) e Cyrino (1993), apontaram o traço de animacidade do referente como explicação para a escolha de uma das duas estratégias de retomada anafórica de terceira pessoa. Mais tarde, Cyrino $(1994, / 1997)$ indica a combinação do traço de animacidade com o traço de especificidade do antecedente como responsáveis pela escolha da estratégia de retomada anafórica. Para ela, um referente [+animado, +específico] tem a tendência a ser retomado por um pronome; em contrapartida, um referente com os traços [-animado, -específico] tem a tendência de ser retomado por uma categoria vazia, um objeto nulo. É o que vemos nos exemplos abaixo, também retirados do nosso corpus de pesquisa:

$$
[-\mathrm{a},-\mathrm{e}]
$$

3. Que o bom era sair com [roupas descartáveis $]_{i}$, em qualquer lugar tu vais largando $\varnothing_{\mathrm{i}}$ e vais comprando $\varnothing_{\mathrm{i}}$, né?

(41. TXT)

$[+\mathrm{a},+\mathrm{e}]$

4. O meu pai viveu até os oitenta anos, e ele era uma pessoa que ele teve pouca instrução, mas, como eu sempre trabalhei fora, e ele ficava com [a minha filha $]_{i}$, ele foi acompanhando ela $a_{i}$ na época escolar.

(RS POA 26 F B SEG)

Creus e Menuzzi (2004, p. 150), por outro lado, entendem que "os efeitos dos traços de animacidade e especificidade mencionados podem ser preditos por uma oposição única: a oposição entre antecedentes que possuem e os que não possuem gênero semântico"'s. Sua hipótese é que, se o antecedente não tiver 2 Em todos os exemplos retirados do corpus, colocaremos a referência da entrevista de onde a ocorrência foi retirada.

3 "Gênero semântico" é entendido aqui como o gênero natural denotado pelo referente. Nesse sentido, referentes como [minha prima], [o João], [meu cachorro Rex] e [a professora]

Revista Letras, têm gênero semântico. Por outro lado, referentes como [a vítima], [o cônjuge], [a mesa que eu

Curitiba, UFPR, n. 96, pp.174-195, jul./dez. 2017. ISSN 2236-0999 (versão eletrônica) 
gênero semântico aparente, será retomado por um ON; caso contrário, por um pronome, como vemos nestes exemplos:

\section{$[+\mathrm{gs}]$}

5. [A guria $]_{\mathrm{i}}$ disparou. Fui encontrar ela $\mathrm{a}_{\mathrm{i}}$ na pensão, que a pensão ficava umas quatro quadras "numa" rua reta lá.

(POA $01 \mathrm{M} \mathrm{B})$

$[-\mathrm{gs}]$

6. Ah, leva [teus roteiros $]_{\mathrm{i}}$ lá pra eu vender $\varnothing_{\mathrm{i}}$ pra ti, né?

(RS POA 31)

Levando em consideração as hipóteses de Cyrino (1994/1997) e de Creus e Menuzzi (2004), pretendemos verificar qual delas tem maior poder explicativo, no sentido de elucidar o fenômeno da retomada anafórica de objeto direto em PB de maneira mais acurada. Verificaremos, também, os traços dos referentes de retomada anafórica de primeira e segunda pessoas (e não apenas de $3^{\text {a }}$ pessoa, como o fazem Cyrino e Creus e Menuzzi), a fim de compreender por que a queda de clítico e a progressiva preferência por objeto nulo em PB acontece quase exclusivamente em casos da terceira pessoa.

\section{O corpus a metodologia}

O corpus que analisamos neste trabalho é composto por 19 entrevistas sociolinguísticas realizadas na cidade de Porto Alegre entre os anos de 1990 e 1999 pertencentes ao projeto VARSUL. Essas entrevistas trazem 19 informantes acima de 25 anos e totalizam 388 páginas de língua falada transcrita, com um total de 112.415 palavras. Nosso primeiro trabalho foi ler as entrevistas transcritas e assinalar as retomadas anafóricas de objeto com pronomes ou ONs. Ao mesmo tempo, identificamos os sintagmas nominais (SNs) antecedentes e os classificamos de acordo com os traços de animacidade, especificidade e gênero semântico, para depois comparar e contrastar os resultados das duas hipóteses com as quais trabalhamos aqui. Consideramos as retomadas anafóricas de $1^{\text {a }}$ pessoa do singular, $2^{\text {a }}$ pessoa do singular e $3^{\text {a }}$ pessoa do singular e do plural, sendo realizadas por clítico, pronome pleno ou categoria vazia, como mostramos nos exemplos abaixo:

comprei] e [um passarinho verde] não possuem gênero semântico. 
G. DE A.

Othero \& A.

C. Spinelli

Analisando

a retomada

anafórica do

objeto direto em português falado

\section{Clítico:}

7. Naquele tempo isso aí - você enxergava [o Guaíba $]_{i}$. Hoje o muro o ${ }_{i}$ tapou.

(RS POA $01 \mathrm{M} \mathrm{B}$ )

Pronome pleno:

8. [A guria $]_{\mathrm{i}}$ disparou. Fui encontrar ela ${ }_{\mathrm{i}}$ na pensão, que a pensão ficava umas quatro quadras "numa" rua reta lá.

(POA $01 \mathrm{M} \mathrm{B})$

\section{Categoria vazia:}

9. Olha, eu soube de [um assalto] $]_{i}$ que teve ali na casa de um - ali na casa do doutor Júlio, mas eu não vi $\varnothing_{\mathrm{i}}$ pra poder contar.

(RS POA 25 F B GIN)

Ainda que tenhamos encontrado outros modos de retomada anafórica do objeto (SN repetido, por exemplo, como em Eu pego [a carne] e eu preparo ela, né. Eu tiro as pelezinhas, tudo, porque aquelas peles deixam [a carne] dura, $n e ́$ ?), consideramos e registramos apenas as três formas mencionadas acima, uma vez que nos interessava verificar o condicionamento da escolha entre ON ou pronome para a retomada anafórica ${ }^{4}$. Classificamos os referentes de cada retomada anafórica encontrada quanto aos traços de animacidade, especificidade e gênero semântico, atribuindo um valor de mais (+) ou menos (-) para cada um deles.

\section{Análise e resultados}

Identificamos 279 ocorrências de retomada anafórica de terceira pessoa, 85 de primeira pessoa do singular e 12 ocorrências de segunda pessoa do singular, totalizando 376 ocorrências de retomadas anafóricas com pronomes ou categorias vazias em função de objeto direto, como resumimos na tabela 1:

Revista Letras,

Curitiba, UFPR, n. 96, pp.174-195, jul./dez. 2017. ISSN 2236-0999 (versão eletrônica)

4 Para um estudo sobre os demais tipos de retomadas anafóricas de objeto em corpus de língua falada, ver, por exemplo, Monteiro (1994) e Vieira Pinto \& Coelho (2016). 


\begin{tabular}{|c|c|c|}
\hline & Ocorrências & Porcentagem \\
\hline $1^{\text {a }}$ pessoa & 85 & $22,6 \%$ \\
\hline $2^{\text {a }}$ pessoa & 12 & $3,2 \%$ \\
\hline $3^{\text {a }}$ pessoa & 279 & $74,2 \%$ \\
\hline Total de ocorrências & 376 & $100 \%$ \\
\hline
\end{tabular}

Tabela 1 - Total de ocorrências de retomadas anafóricas no corpus.

Separamos esta seção em três partes: a primeira destinada à $1^{\text {a }}$ pessoa, a segunda à $2^{\text {a }}$ pessoa e a terceira reservada para a $3^{\text {a }}$ pessoa.

\subsection{Retomada anafórica de $1^{\mathrm{a}}$ pessoa do singular}

Comecemos com os dados da $1^{\text {a }}$ pessoa do singular. Entre os resultados encontrados nesta categoria, obtivemos 80 ocorrências de retomada anafórica por meio de clítico, 4 retomadas por meio de objeto nulo e apenas 1 com pronome pleno, como se vê na tabela 2 e como atestam os exemplos a seguir:

\begin{tabular}{|c|c|c|}
\hline & Ocorrências & Porcentagem \\
\hline ON & 4 & $4,7 \%$ \\
\hline Pronome pleno & 1 & $1,2 \%$ \\
\hline Pronome clítico & $\mathbf{8 0}$ & $\mathbf{9 4 , 1} \%$ \\
\hline Total de ocorrências & 85 & $100 \%$ \\
\hline
\end{tabular}

Tabela 2 - Total de ocorrências de retomadas anafóricas de primeira pessoa no corpus.

ON:

10. Bom, eu já trabalhava, e uns vizinhos meus tinham casa em Guaíba, na praia da Florida, e esses vizinhos tinham uma moça, e a moça estava achando muito monótono ir com os pais pra lá. Aí ela convidou $\varnothing$. Como eu tinha férias, mas não tinha rumo, eu fui e passei uns dias com eles.

(RS POA 26 F B SEG)

Pronome pleno:

11. A minha irmã mais velha que criou eu.

(RS POA $27 \mathrm{M}$ ) 
G. DE A.

OTHERO \& A.

C. SPINELli

Analisando

a retomada

anafórica do

objeto direto em português falado

\section{Clítico:}

12. Em seguida que eu me formei eu fiz um concurso. Passei; nunca me chamaram.

(RS POA 31)

Esses resultados diferem radicalmente dos de terceira pessoa (que apresentaremos adiante): com a primeira pessoa, os pronomes clíticos são a estratégia dominante de retomada anafórica ( $94,1 \%$ dos casos, como vimos). Esse resultado era esperado, como já apontaram estudos anteriores (cf. MONTEIRO, 1994; SCHWENTER, 2006, OTHERO; CARDOZO, 2017).

Realizamos a análise dos traços dos referentes de cada retomada anafórica e os separamos de acordo com as duas hipóteses de condicionamento que estamos comparando aqui, a saber: a combinação dos traços de animacidade e especificidade versus a hipótese do traço de gênero semântico do referente. Os resultados obtidos encontram-se nas tabelas 3 e 4 abaixo e são, obviamente, muito pouco ilustrativos:

\begin{tabular}{|c|c|c|c|}
\hline $\begin{array}{c}\text { Traços do refe- } \\
\text { rente }\end{array}$ & Objeto Nulo & Pronome & Total \\
\hline$[+\mathrm{a},+\mathrm{e}]$ & $4(4,7 \%)$ & $81(95,3 \%)$ & $85(100 \%)$ \\
\hline$[+\mathrm{a},-\mathrm{e}]$ & 0 & 0 & 0 \\
\hline$[-\mathrm{a},+\mathrm{e}]$ & 0 & 0 & 0 \\
\hline$[-\mathrm{a},-\mathrm{e}]$ & 0 & 0 & 0 \\
\hline
\end{tabular}

Tabela 3 - Distribuição, para $1^{\text {a }}$ pessoa, de objeto nulo vs. pronome com antecedente

$$
[ \pm \mathrm{a}, \pm \mathrm{e}] \text {. }
$$

\begin{tabular}{|c|c|c|c|}
\hline Traços do referente & ON & Pronome & Total \\
\hline$[+$ gs $]$ & $4(4,7 \%)$ & $81(95,3 \%)$ & $85(100 \%)$ \\
\hline$[-g s]$ & 0 & 0 & 0 \\
\hline
\end{tabular}

Tabela 4 - Antecedentes de retomadas anafóricas de $1^{\text {a }}$ pessoa classificados com base no traço de gênero semântico.

Não encontramos diferenças ao comparar as duas hipóteses para o condicionamento da escolha de pronome $v$ s. objeto nulo na primeira pessoa do singular: a combinação dos traços $[ \pm a, \pm e]$ traz o mesmo resultado da análise realizada a partir do traço $[ \pm \mathrm{gs}]$, que é a preferência pela retomada com pronome clítico. Ou seja, na retomada anafórica de primeira pessoa do singular (“eu”), sempre sabemos que o antecedente é, ao mesmo tempo, animado, específico e que possui gênero semântico. Isso faz com que essa retomada seja preferencialmente

Revista Letras,

Curitiba, UFPR, n. 96, pp.174-195, jul./dez. 2017. ISSN 2236-0999 (versão eletrônica) 
feita por pronomes (em contraste com ONs): 95,3\% dos casos (contra apenas $4,7 \%$ ocorrências de $\mathrm{ON}$ ). Passemos, então, aos dados referentes à retomada anafórica de $2^{\mathrm{a}}$ pessoa.

\subsection{Retomada anafórica de $2^{\mathrm{a}}$ pessoa do singular}

Nos dados de segunda pessoa do singular, também verificamos uma preferência por pronome clítico; porém, a distribuição dos traços dos referentes foi um pouco diferente, graças a uma ocorrência significativa do chamado te genérico, que mostramos nos exemplos abaixo:

13. Aquela banca tinha assim eram três professores examinando, tirava a questão, um ponto sorteado, e $t u$ sentavas pra ficar pensando, aí então eles $\varnothing$ chamavam e tu passavas pelos três, cada um com uma das questões do ponto, né? (RS POA 31)

14. Se $t u$ chegas bastante mal, eles te atendem. Tu chegas atropelado, tu chegas aos berros com um apêndice supurando, qualquer coisa assim, tu és atendido.

Esses exemplos são interessantes porque aqui o pronome tu e sua retomada anafórica não estão apontando para o interlocutor, i.e., eles perderam seu caráter dêitico e mostrativo na situação de interlocução; antes, eles estão sendo usados no sentido genérico (cf. CUNHA, 1993). Os exemplos acima (como todos os exemplos que apresentamos no texto) foram retirados de um trecho de fala do informante, em diálogo com um entrevistador. Repare que nenhuma dessas ocorrências de $t u$ se refere ao entrevistador, mas a alguém de maneira genérica (note também que não temos casos de você, mas apenas de $t u$, uma marca do falar de Porto Alegre, de maneira específica, e do dialeto gaúcho, de maneira geral cf. BAGNO, 2011; LOREGIAN-PENKAL, 2014; PERINI, 2016). De qualquer maneira, esses são casos interessantes porque - ao contrário dos pronomes sendo usados referencial e exoforicamente, que se dirigem diretamente ao interlocutor -, aqui temos referentes não específicos [-e] e com o gênero semântico não transparente [-gs]. Nesses casos, ao contrário do que vimos com os pronomes de $1^{\text {a }}$ pessoa, teremos, então, referentes [+a, -e] e [-gs], como mostramos nas tabelas 5 e 6 abaixo: 
G. DE A.

OTHERO \& A.

C. SPINELli

Analisando

a retomada

anafórica do

objeto direto em português falado

\begin{tabular}{|c|c|c|c|}
\hline $\begin{array}{c}\text { Traços do refe- } \\
\text { rente }\end{array}$ & Objeto Nulo & Pronome & Total \\
\hline$[+\mathrm{a},+\mathrm{e}]$ & 0 & $8(100 \%)$ & 8 \\
\hline$[+\mathrm{a},-\mathrm{e}]$ & $1(25 \%)$ & $3(75 \%)$ & 4 \\
\hline$[-\mathrm{a},+\mathrm{e}]$ & 0 & 0 & 0 \\
\hline$[-\mathrm{a},-\mathrm{e}]$ & 0 & 0 & 0 \\
\hline
\end{tabular}

Tabela 5 - Distribuição, para segunda pessoa, de objeto nulo vs. pronome com antecedente $[ \pm \mathrm{a}, \pm \mathrm{e}]$.

\begin{tabular}{|c|c|c|c|}
\hline $\begin{array}{c}\text { Traços do refe- } \\
\text { rente }\end{array}$ & ON & Pronome & Total \\
\hline$[+\mathrm{gs}]$ & 0 & $8(100 \%)$ & 8 \\
\hline$[-\mathrm{gs}]$ & $1(25 \%)$ & $3(75 \%)$ & 4 \\
\hline
\end{tabular}

Tabela 6 - Antecedentes de retomadas anafóricas de segunda pessoa classificados com base no traço de gênero semântico.

Infelizmente, temos poucas ocorrências de pronomes de $2^{\text {a }}$ pessoa em função de objeto direto no corpus (apenas 12), o que nos impede de tirar generalizações sólidas. De todo modo, repare como em todos os casos em que o referente tem o traço [+gs], ele é retomado por um pronome, como vemos no exemplo (15) abaixo. Por outro lado, o único caso de retomada anafórica com ON em segunda pessoa acontece justamente com um referente [-gs], apesar de ser $[+\mathrm{a}]$ (como visto no exemplo (13) acima).

15. Não, meu filho, tu vais ser o que tu quiser, ora, não vou te obrigar a ser uma coisa que tu não queiras, ora.

(RS POA 27)

Passemos, finalmente, aos dados referentes às retomadas anafóricas de $3^{\text {a }}$ pessoa.

\subsection{Retomada anafórica de $3^{\mathrm{a}}$ pessoa}

Como vimos no início desta seção, encontramos 279 ocorrências de retomada anafórica de $3^{\text {a }}$ pessoa: 218 foram casos de ON, 51 ocorrências foram registradas com pronome pleno e apenas 10 clíticos foram encontrados, como ilustramos com os exemplos abaixo:

Revista Letras,

Curitiba, UfPR, n. 96, pp.174-195, jul./dez. 2017. ISSN 2236-0999 (versão eletrônica) 
Objeto nulo:

16. É o grupo escolar Evarista Flores da Cunha, que é o nome da mãe do General José Antônio Flores da Cunha, que na oportunidade foi quem mandou construir [aquele prédio], né? Que é um lindo prédio, não sei se cê conhece $\varnothing_{\mathrm{i}}$. (RS POA 35 MB SUP)

Pronome pleno:

17. Na São Borja, quando eu estava voltando, tinha que passar um pontilhão ali perto do Colégio Liberato, dá [um cara $]_{\mathrm{i}}$ veio, quis me tirar a jaqueta e as calças, mas ele estava muito perto, daí eu consegui empurrar ele ${ }_{i}$ pra dentro do valo. (RS POA $27 \mathrm{M}$ )

Pronome clítico:

18. Tenho até [um computadorzinho] $]_{i}$ ali. Agora sob o aspecto prático, não há dúvida, né? Resolve problemas de muita rapidez, o que a pessoa precisa saber mesmo é operá- $\mathrm{l}_{\mathrm{i}}$.

(RS POA 35 MB SUP)

Ilustramos essa distribuição da retomada anafórica de $3^{\text {a }}$ pessoa com o gráfico 1 abaixo:

\section{Retomada anafórica de 3a pessoa}

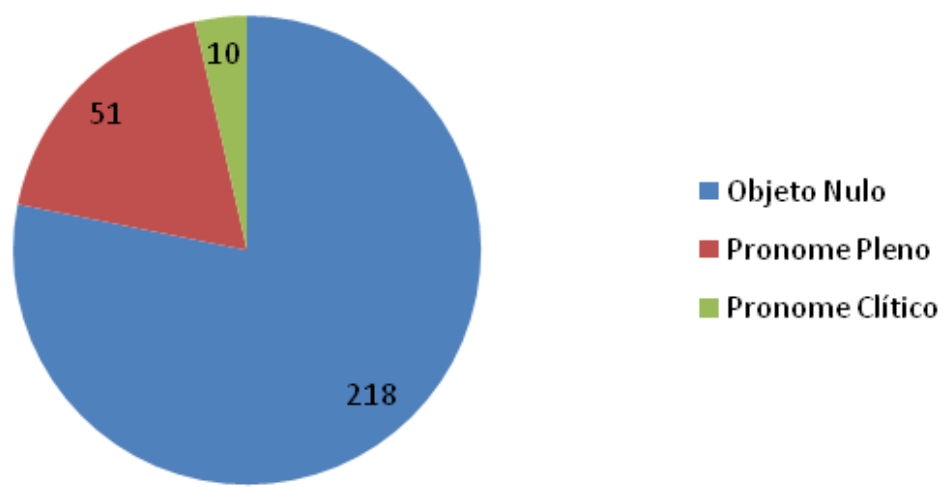

Gráfico 1 - Distribuição das ocorrências de retomadas anafóricas de $3^{\text {a }}$ pessoa.

O primeiro fato que salta aos olhos é que o objeto nulo é a estratégia mais utilizada na amostra de corpus de língua falada que estudamos, confirmando estudos anteriores, como Tarallo (1983), Monteiro (1994) e Bagno (2011), por exemplo. Outra observação que já está também ancorada em achados anteriores 
G. DE A. é a de que os clíticos de $3^{\text {a }}$ pessoa estão de fato em desuso, perdendo seu espaço

OTHERO \& A.

C. SPINELli

Analisando

a retomada

anafórica do

objeto direto em português falado justamente para o ON e para os pronomes plenos na retomada anafórica de objeto - cf. trabalhos já citados.

Resta-nos investigar agora os traços semânticos e discursivos que condicionam essas duas estratégias "inovadoras" de retomada do objeto (ON e pronomes plenos) $)^{5}$. Comecemos analisando as ocorrências de $\mathrm{ON}$ e pronomes com base nos traços de animacidade e especificidade dos antecedentes (à la CYRINO, 1994/1997; SCHWENTER; SILVA, 2002, entre outros). Depois, analisemos os antecedentes com base no traço de gênero semântico (seguindo a hipótese de Creus e Menuzzi 2004).

\subsubsection{Animacidade e especificidade dos antecedentes}

Das 279 ocorrências de retomadas anafóricas de $3{ }^{a}$ pessoa que encontramos, separamos os antecedentes de acordo com seus traços de animacidade e especificidade, tal como apresentamos na tabela 7, que segue abaixo dos exemplos:

$$
[+\mathrm{a},+\mathrm{e}]
$$

19. O meu pai viveu até os oitenta anos, e ele era uma pessoa que ele teve pouca instrução, mas, como eu sempre trabalhei fora, e ele ficava com [a minha filha $]_{i}$, ele foi acompanhando ela $a_{i}$ na época escolar.

(RS POA 26 F B SEG)

$[+\mathrm{a},-\mathrm{e}]$

20. Esse pessoal que vem do interior, geralmente noventa por cento é do interior, então eles pegam [o pessoal $]_{\mathrm{i}} \mathrm{e}$ largam $\varnothing_{\mathrm{i}}$ ali e babaus.

(RS POA 03 M A PRI)

$$
[-\mathrm{a},+\mathrm{e}]
$$

21. Então eu tenho esse trabalho aí, até pra listar, pra publicar. Eu que pesquisei $\varnothing_{\mathrm{i}}$, procurei $\varnothing_{\mathrm{i}}$, achei $\varnothing_{\mathrm{i}}$ e gostei. (RS POA $35 \mathrm{M} \mathrm{B}$ SUP)

Revista Letras,

Curitiba, UFPR, n. 96, pp.174-195, jul./dez. 2017. ISSN 2236-0999 (versão eletrônica)

5 Como mencionamos ao longo do trabalho, levaremos em consideração aqui apenas fatores "gramaticais" no condicionamento da retomada anafórica de objeto - e não fatores sociais ou extralinguísticos. Cf. Monteiro (1994) e Pinto e Coelho (2016), por exemplo, para uma abordagem que leva em conta fatores sociais. Monteiro (1994) analisa dados de fala do projeto Norma Urbana Culta (NURC), das cidades de Porto Alegre, Rio de Janeiro, São Paulo, Recife e Salvador; e Pinto e Coelho (2016) analisam dados do corpus do VARSUL e da Amostra Floripa (que é composta por 39 entrevistas sociolinguísticas realizadas em Santa Catarina). 
$[-\mathrm{a},-\mathrm{e}]$

22. Naquela época foi também pra fazer negócio: naquela época se comprava [automóvel] $]_{\mathrm{i}}$ lá mais barato pra revender $\varnothing_{\mathrm{i}}$ aqui. (RS POA $26 \mathrm{~F} \mathrm{~B} \mathrm{SEG)}$

\begin{tabular}{|l|l|l|l|}
\hline Traços do referente & Objeto Nulo & Pronome & Total \\
\hline$[+\mathrm{a},+\mathrm{e}]$ & $20(33 \%)$ & $41(67 \%)$ & 61 \\
\hline$[+\mathrm{a},-\mathrm{e}]$ & $8(100 \%)$ & $0(0 \%)$ & 8 \\
\hline$[-\mathrm{a},+\mathrm{e}]$ & $140(95 \%)$ & $7(5 \%)$ & 147 \\
\hline$[-\mathrm{a},-\mathrm{e}]$ & $50(94 \%)$ & $3(6 \%)$ & 53 \\
\hline
\end{tabular}

Tabela 7 - Distribuição de objeto nulo $v$ s. pronome com antecedente $[ \pm \mathrm{a}, \pm \mathrm{e}]$.

Repare, na tabela 7, que destacamos em negrito as tendências: se o antecedente for $[+\mathrm{a},+\mathrm{e}]$, terá a tendência de ser retomado por pronome; caso contrário $([+\mathrm{a},-\mathrm{e}],[-\mathrm{a},+\mathrm{e}]$ ou $[-\mathrm{a},-\mathrm{e}])$ por $\mathrm{ON}-$ estamos aqui lidando com os dados brutos, sem tratamento estatístico (que não realizamos por falta de tempo, nostra culpa). Essa tabela pode ser mais bem visualizada no gráfico 2 abaixo:

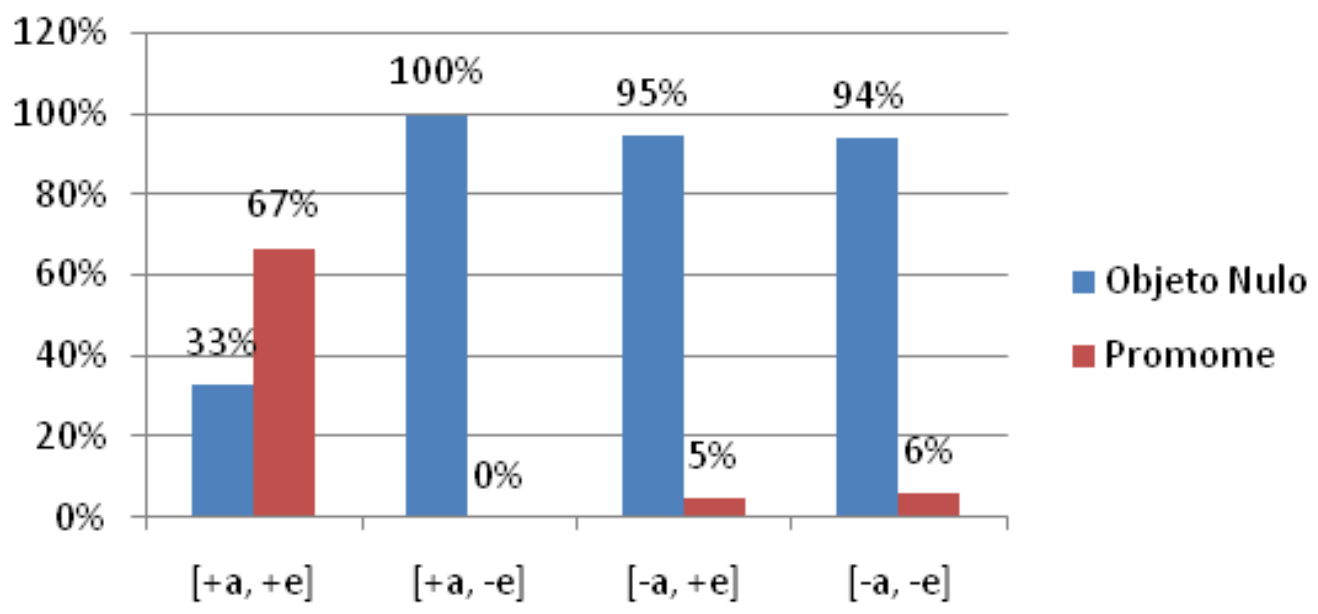

Gráfıco 2 - Distribuição objeto nulo vs. pronome com antecedentes [ $\pm \mathrm{a}, \pm \mathrm{e}]$.

Esses resultados são parcialmente condizentes com o que já encontramos na literatura sobre o assunto. Um fator interessante aqui é o alto índice de retomadas com ON, mesmo em casos em que os referentes têm os traços $[+a,+e]$ - quase um terço dos casos. Em trabalhos que analisaram corpora escritos (como CYRINO, 1994/1997; PIVETTA, 2015 e OTHERO; SCHWANKE, 2016, por exemplo), encontramos resultados mais categóricos no sentido de que os referentes [+a, +e] são retomados por pronomes na quase totalidade dos casos - mas ver observações nos próximos parágrafos. Contudo, em trabalhos que analisam dados de fala, encontramos, de fato, diversas ocorrências de ON retomando referentes [+a, +e], como podemos ver em Schwenter e Silva (2003), Ayres (2016) e Vieira Pinto e Coelho (2016), por exemplo. A nosso ver, isso pode mostrar que 
G. DE A.

Othero \& A.

C. SPINELli

Analisando

a retomada

anafórica do

objeto direto em português falado i) o ON é uma estratégia que vem ganhando espaço no vernáculo brasileiro $^{6}$;

ii) antecedentes $[+a,+e]$ não condicionam categoricamente a retomada anafórica pronominal7.

Uma outra "novidade" aqui diz respeito às retomadas anafóricas de referentes com traços [+a, -e] (apenas 8 ocorrências em nosso corpus, ver exemplo 20). Cyrino (1994/1997), Pivetta (2015) e Schwanke (2016) também encontraram poucas ocorrências desse tipo de antecedente: 7 na pesquisa de Cyrino, 8 na de Pivetta e 4 nos dados de Schwanke. Contudo, nossos resultados são bem distintos: todos os antecedentes [+a, -e] foram retomados por ONs (100\%), ao passo que Cyrino (1994/1997) encontrou 57,1\% de ocorrências de ON para a retomada de antecedentes com o traço [+a, -e]; Pivetta (2015) 37,5\% de ONs e Schwanke (2016), por sua vez, encontrou uma preferência por pronome quando do traço [+a, -e] do antecedente ( $25 \%$ de retomada anafórica com ON contra $75 \%$ de ocorrências com pronomes). Ou seja, esse é um forte indicador de que a combinação entre os traços de animacidade e especificidade não é uma hipótese sólida ou categórica para explicar a distribuição entre pronomes e ONs na retomada anafórica de $3^{\text {a }}$ pessoa em PB. Os antecedentes [+a, -e] são reconhecidamente o calcanhar-deaquiles da hipótese que envolve os traços de animacidade e especificidade (cf. CREUS; MENUZZI, 2004; PIVETTA, 2015).

Da mesma forma que verificado em trabalhos anteriores, nossos resultados também apontam para o favorecimento do uso de objetos nulos quando o antecedente for marcado negativamente para o traço de animacidade, independentemente de sua classificação quanto ao traço de especificidade, mostrando que o traço de especificidade é, por vezes, irrelevante e tem papel secundário ou redundante quando combinado com a animacidade do antecedente. Ou seja:

$$
\begin{aligned}
& \text { essa relação íntima dos dois traços [animacidade e } \\
& \text { especificidade] no condicionamento da alternância entre }
\end{aligned}
$$

6 Confirmando, então, as hipóteses de Monteiro (1994), Duarte (1989), Cyrino (1994/1997, 2013), Schwenter \& Silva (2002, 2003), Casagrande (2007), Bagno (2011), Ayres (2016), entre outros.

7 Isso é novidade, já que os trabalhos anteriores, que levaram em consideração a língua escrita, costumavam afirmar que antecedentes $[+\mathrm{a},+\mathrm{e}]$ condicionavam categoricamente a retomada anafórica via pronome. $\mathrm{Na}$ fala infantil, também encontramos o ON como estratégia generalizada. Aliás, nos dados de Ayres (2016), por exemplo, que analisa a fala de 36 crianças entre 1 e 9 anos de idade, os antecedentes com os traços $[+\mathrm{a},+\mathrm{e}]$ são retomados preferencialmente por ONs (em $72,8 \%$ dos casos), ao passo que a retomada anafórica pronominal é responsável por apenas $27,2 \%$ dos casos.
Revista Letras,

Curitiba, UFPR, n. 96, pp.174-195, jul./dez. 2017. ISSN 2236-0999 (versão eletrônica) 
pronomes e ONs sugere que a ação dos dois traços não é autônoma, mas o resultado de generalizações mais básicas (CREUS; MENUZZI, 2004, p. 5).

Tomando o traço de animacidade como o centro da combinação dos dois traços citados e levando em conta que o aspecto fundamental desse traço é sua associação com distinções de gênero semântico, Creus e Menuzzi (2004) propuseram a reformulação das generalizações básicas do sistema de anáfora de objeto no PB a partir da presença ou ausência de gênero semântico no antecedente. $\mathrm{Na}$ próxima subseção, analisaremos os mesmos dados do nosso corpus sob o viés desse traço, [ $\pm \mathrm{gs}]$.

\subsubsection{Gênero semântico dos antecedentes}

Nesta seção, apresentamos nossa análise dos antecedentes com base no traço de gênero semântico. Dos 279 antecedentes que encontramos no corpus, 51 foram marcados com [+gs] e 228 foram marcados com o traço [-gs]. Ou seja, a retomada anafórica de objetos acontece majoritariamente com referentes sem gênero semântico (81,7\%), em consonância com o que apontaram Othero et al. (2016). Apresentamos, a seguir, exemplos de fala transcrita em que o referente é analisado quanto ao seu gênero semântico:

\section{$[+g s]$}

23. E o [Homero $]_{\mathrm{i}}$ dormindo lá em cima com o berro na mão lá, e eu ferrado aqui embaixo. É brincadeira. [...] Eu ia chamar ele i, no mínimo, né.

(RS POA 03 M A PRI)

\section{$[-\mathrm{gs}]$}

24. Ah, leva [teus roteiros] lá pra eu vender $\varnothing_{\mathrm{i}}$ pra ti, né?

(RS POA 31)

Abaixo, sistematizamos parte dos resultados em uma tabela e em um gráfico:

\begin{tabular}{|l|l|l|l|}
\hline Traço do referente & ON & Pronome & Total \\
\hline$[+$ gs $]$ & $10(19 \%)$ & $41(81 \%)$ & $51(100 \%)$ \\
\hline$[-$ gs $]$ & $208(91 \%)$ & $20(9 \%)$ & $228(100 \%)$ \\
\hline
\end{tabular}

Tabela 8 - Antecedentes classificados com base no traço de gênero semântico. 
G. DE A.

OTHERO \& A.

C. SPINELli

Analisando

a retomada

anafórica do

objeto direto em português falado

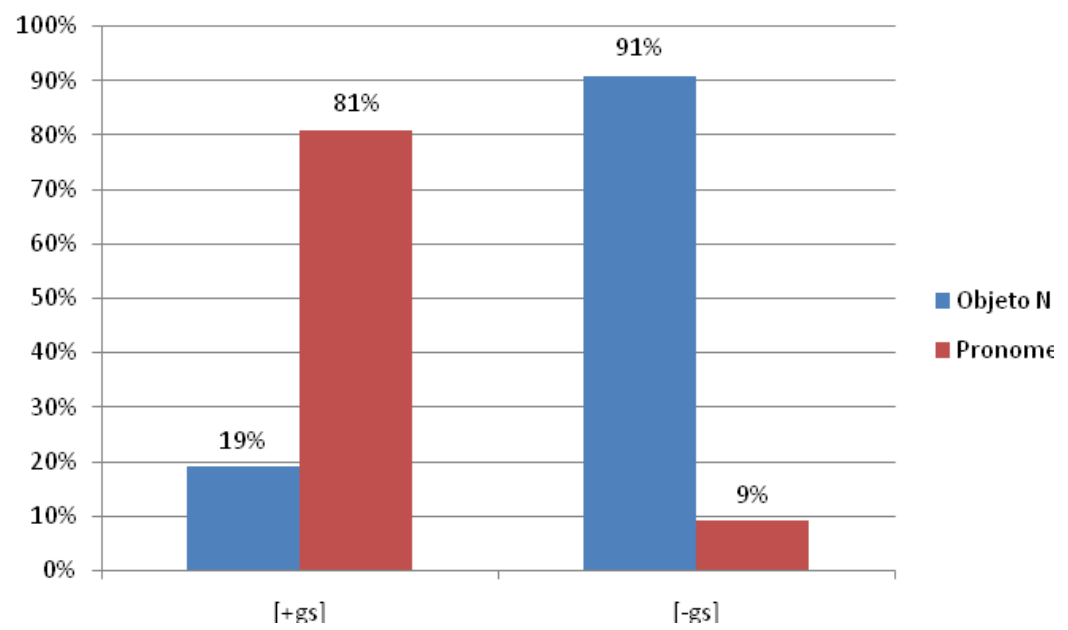

Gráfico 3 - Antecedentes classificados com base no traço de gênero semântico.

Como podemos ver no gráfico 3 acima, encontramos uma forte tendência de que os antecedentes marcados com [+gs] sejam retomados por pronomes, ainda que o resultado não seja categórico (81\%). Quando o referente é marcado com o traço [-gs], está claro que existe uma tendência categórica de $91 \%$ de que a retomada se dê por meio de um ON. É fácil perceber que aqui, com apenas o traço de gênero semântico, a polarização dos resultados fica evidente compare o gráfico 3 com o gráfico 2 , em que tínhamos os traços de animacidade e especificidade do referente e que não traziam uma polarização tão clara dos dados.

Se reanalisarmos os resultados encontrados por Creus e Menuzzi (2004) ao aplicarem seu teste (cf. CREUS; MENUZZI, 2004) e compararmos tais resultados com os nossos, notaremos a confirmação da hipótese de que o único traço relevante do antecedente no que toca à retomada anafórica de objeto em PB é, de fato, o gênero semântico. Observe as tabelas 9 (com os dados de Creus e Menuzzi) e 10 (com nossos dados) a seguir:

\begin{tabular}{|l|l|l|}
\hline Classe do Antecedente & Objetos Nulos & Pronomes \\
\hline$[+\mathrm{a}-\mathrm{e},-\mathrm{gs}]$ & $24 / 37(64,9 \%)$ & $13 / 37(35,1 \%)$ \\
\hline$[+\mathrm{a},-\mathrm{e},+\mathrm{gs}]$ & $09 / 31(29 \%)$ & $22 / 31(71 \%)$ \\
\hline
\end{tabular}

Tabela 9 - Ocorrência de ONs e pronomes segundo antecedentes [+a, -e] (adaptado de CREUS; MENUZZI, 2004, p. 9).

A tabela 9 apresenta um fator decisivo para compreender o gênero semântico como condicionador da alternância entre $\mathrm{ON}$ e pronome: nas duas primeiras combinações de antecedentes (a saber, [+a, -e, -gs] e [+a, -e, +gs]) o único diferencial é o traço de gênero semântico. Na primeira combinação, em que os referentes são [-gs], observamos quase $65 \%$ de ocorrência de objetos nulos e apenas $35 \%$ de ocorrências de retomada por pronome. Ainda que não
Revista Letras,

Curitiba, UFPR, n. 96, pp.174-195, jul./dez. 2017. ISSN 2236-0999 (versão eletrônica) 
pareça um resultado relevante por não ser categórico, ele ganha destaque quando comparado com a segunda combinação de traços do antecedente, que contém os mesmos traços de animacidade e especificidade, porém se diferencia pela marca positiva para gênero semântico. Nessa combinação, 71\% das retomadas anafóricas ocorreram com o uso de pronome, uma porcentagem bastante diferente da encontrada para a primeira combinação. Ou seja: os antecedentes [+a, -e] são problemáticos; aqui o efeito do traço de gênero semântico se mostra especialmente revelador.

Como havíamos mencionado anteriormente, tivemos poucas ocorrências de antecedentes com os traços [+a, -e], apenas 8. Entretanto, obtivemos um resultado interessante (e categórico) com esse tipo de antecedente:

\begin{tabular}{|l|l|l|l|}
\hline Traços do referente & Objeto Nulo & Pronomes & TOTAL \\
\hline$[+\mathrm{a},-\mathrm{e},-\mathrm{gs}]$ & $8(100 \%)$ & 0 & 8 \\
\hline$[+\mathrm{a},-\mathrm{e},+\mathrm{gs}]$ & 0 & 0 & 0 \\
\hline
\end{tabular}

Tabela 10 - Ocorrência de ONs e pronomes segundo antecedentes [+a, -e].

Repare, na tabela 10, que esse tipo de antecedente foi, de certa forma, problemático para os estudos de Cyrino (1994/1997), Pivetta (2015) e Schwanke (2016) (e mesmo para Creus e Menuzzi (2004)), já que nenhum deles trouxe dados categóricos de distribuição clara na retomada anafórica (ON x pronomes). Aqui, ao contrário, encontramos dados categóricos e reveladores: o traço de gênero semântico parece ser, de fato, o traço definitivo e responsável pela distribuição entre ONs e pronomes na retomada anafórica de $3^{\text {a }}$ pessoa com antecedentes [+a, -e], algo previsto (mas não corroborado empiricamente de maneira contundente) por Creus e Menuzzi (2004).

Além disso, apenas com o traço de gênero semântico do antecedente já podemos visualizar melhor a polarização da retomada anafórica (cf. novamente o gráfico 3): ainda que não tenhamos uma conclusão categórica, nossos resultados (juntamente com os resultados encontrados por Creus e Menuzzi, 2004 e Othero et al., 2016) apontam para a preferência do uso de pronome na retomada de referentes marcados positivamente para o gênero semântico (81\%) e o grande favorecimento (91\%) do objeto nulo na retomada de referentes marcados negativamente para esse traço.

Por fim, efetuamos um cruzamento inverso, para verificar qual a preferência de antecedente no caso de um $\mathrm{ON}$ e de um pronome em retomada anafórica. Essa inversão de perspectiva confirmou os resultados que encontramos até aqui, ou seja: vemos uma forte tendência de ter objetos nulos retomarem antecedentes [-gs], ao passo que os pronomes se referem, em sua maioria, a antecedentes [+gs], como sistematizamos no gráfico 4 , abaixo, e na tabela subsequente: 
G. DE A.

Othero \& A.

C. Spinelli

Analisando

a retomada

anafórica do

objeto direto em português falado

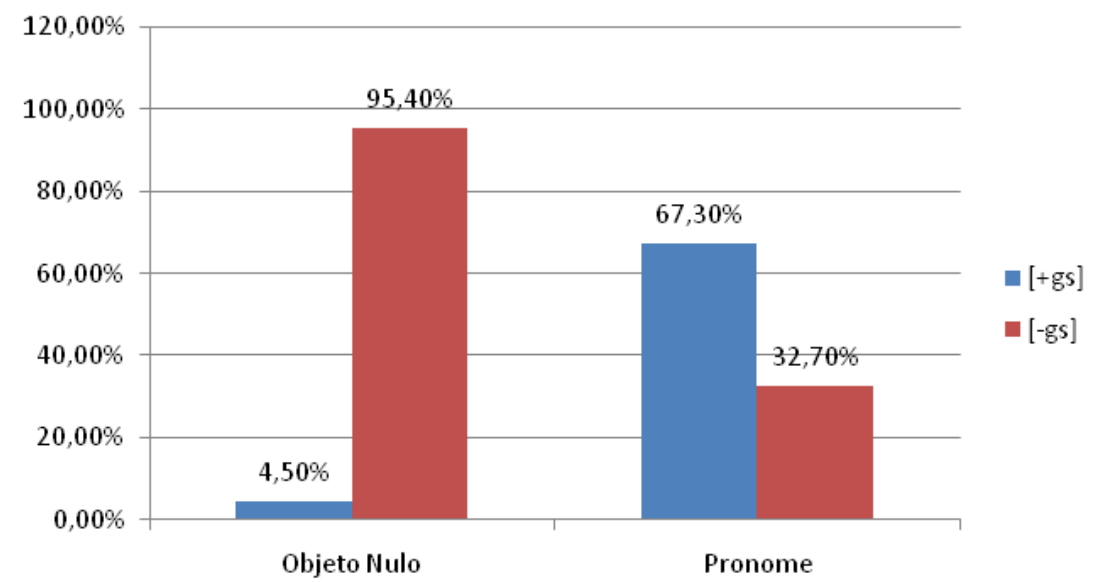

Gráfıco 4 - Tipos de retomada e seus antecedentes.

\begin{tabular}{|l|l|l|l|}
\hline Tipo de retomada & {$[+\mathrm{gs}]$} & {$[-\mathrm{gs}]$} & Total \\
\hline ON & $10(4,5 \%)$ & $208(95,4 \%)$ & $218(100 \%)$ \\
\hline Pronome & $41(67,3 \%)$ & $20(32,7 \%)$ & $61(100 \%)$ \\
\hline
\end{tabular}

Tabela 11 - Tipos de retomada e seus antecedentes.

Observando a tabela 11 e o gráfico 4, podemos concluir sobre a preferência da ocorrência de objeto nulo quando o antecedente é marcado com o traço [-gs], chegando a quase $100 \%$ das ocorrências encontradas. Por outro lado, percebemos apenas uma tendência de que referentes com traço [+gs] sejam retomados por pronome. Essa tendência ainda não nos indica uma polarização categórica, e os motivos ainda devem ser investigados.

\subsubsection{Síntese}

Comparando nossos resultados com estudos anteriores acerca da combinação de traços $[ \pm a, \pm$ e] como condicionadora do uso de pronomes e objetos nulos, não encontramos uma polarização que nos permitisse explicar a sistemática da retomada anafórica de terceira pessoa por meio dessa combinação de traços. Ainda que tenhamos verificado que antecedentes não animados favorecem o ON, não podemos afirmar que existe uma preferência de retomada para a combinação do traço de animacidade com o de especificidade do antecedente.

Por outro lado, verificamos que o traço de gênero semântico do antecedente nos permite polarizar melhor os resultados: de todas as ocorrências de retomada com objeto nulo, mais de 95\% apontam para referentes com o traço [-gs]. Isso confirma a hipótese de Creus e Menuzzi (2004), a saber: as generalizações básicas do sistema de anáfora de objeto do $\mathrm{PB}$ podem ser reformuladas a partir da presença ou ausência do traço de gênero semântico do antecedente. A explicação por meio da hipótese do gênero semântico parece-nos mais adequada porque, além de ter apresentado resultados mais polarizados, é uma maneira mais econômica de
Revista Letras,

Curitiba, UFPR, n. 96, pp.174-195, jul./dez. 2017. ISSN 2236-0999 (versão eletrônica) 
explicar este fenômeno da língua; afinal, utiliza a análise de apenas um traço ao invés de recorrer à combinação de dois ou mais traços - Navalha de Occam! Além disso, a hipótese segue os princípios de concordância da língua:

\begin{abstract}
Do ponto de vista conceitual, a hipótese que associa os pronomes plenos do $\mathrm{PB}$ à presença de gênero semântico, e objetos nulos à ausência de gênero semântico é mais natural que a hipótese análoga baseada na distinção de animacidade: afinal, a diferença básica entre as formas ele/ela e os objetos nulos é que as primeiras portam especificações de gênero, enquanto que os últimos são justamente não-especificados para gênero (bem como para número, mas nisso os ONs não diferem significativamente dos PrPls, já que os últimos podem ou não portar a flexão de número). Ou seja, a escolha entre ONs e PrPls resultaria, basicamente, de um processo de concordância entre antecedente e forma anafórica: antecedentes com gênero semântico favorecem o uso de PrPls porque estas são as formas anafóricas especificadas para gênero; e antecedentes sem gênero semântico favorecem o uso de ONs precisamente porque ONs não possuem especificação para gênero semântico. (CREUS; MENUZZI, 2004, p.161).
\end{abstract}

Ou seja, os pronomes plenos ele/ela portam especificações de gênero, ao passo que os objetos nulos não têm especificação de gênero, retomando, portanto, em sua maioria, antecedentes de traço [-gs].

\title{
Considerações finais
}

Investigamos aqui duas estratégias de retomada anafórica em português falado, em sua variedade de Porto Alegre. Analisamos os traços de animacidade, especificidade e gênero semântico do referente de cada uma das 376 ocorrências de retomada anafórica (com pronomes ou categorias vazias) em função de objeto direto que encontramos no corpus analisado (19 entrevistas de Porto Alegre do banco de dados do projeto VARSUL). Nosso objetivo principal foi verificar qual a motivação da escolha do uso de pronome ou categoria vazia para a retomada anafórica de terceira pessoa, comparando as hipóteses de Cyrino (1994/1997) e de Creus e Menuzzi (2004).

Adicionalmente, pesquisamos as ocorrências de retomadas anafóricas de $1^{\text {a }}$ e $2^{\text {a }}$ pessoas do singular. Com isso confirmarmos que, conforme relatam Monteiro (1994), Nunes (1996) e Othero e Cardozo (2017), os clíticos não estão 
G. DE A. "desaparecendo" - apenas os clíticos pronominais de $3^{\text {a }}$ pessoa estão em desuso. OTHERO \& A. Em primeira e segunda pessoas, o pronome clítico mantém sua predominância

C. SpinelLi

Analisando

a retomada

anafórica do

objeto direto em português falado no que se refere à retomada anafórica, e uma parte da explicação para isso se deve ao fato de que os referentes anafóricos para quem esses pronomes apontam são (quase) sempre [+a], [+e] e [+gs]; afinal, são sujeitos do discurso (à exceção do tu genérico, como vimos). Esses traços dos antecedentes favorecem a manutenção (e não o apagamento) do pronome. Isso explica por que não encontramos muitas ocorrências de ONs com $1^{\text {a }}$ e $2^{\text {a }}$ pessoas. Mas isso não explica por que encontramos mais clíticos pronominais do que pronomes tônicos cumprindo essa função (não nos compete desenvolver essa ideia aqui, mas acreditamos que fatores de natureza prosódica estejam envolvidos, bem como fatores ligados à reestruturação do quadro pronominal em $\mathrm{PB}$, tal como apontam Monteiro (1994), Nunes (1996) e Othero e Cardozo (2017).

$\mathrm{Na}$ análise de terceira pessoa, chegamos à conclusão de que um único traço - o de gênero semântico - pode explicar as estratégias de retomada anafórica com pronome ou objeto nulo: se o antecedente for [-gs], teremos a tendência de retomá-lo com uma categoria vazia; se o antecedente possuir o traço [+gs], usaremos um pronome - não se trata, contudo, de um fenômeno de distribuição completar do tipo "tudo-ou-nada", mas uma tendência forte na língua, como vimos. Também acreditamos que a hipótese do gênero semântico se mostra uma maneira mais econômica para explicar o fenômeno em questão e vai ao encontro dos princípios de concordância, já que os pronomes de terceira pessoa elelela carregam especificações de gênero, sendo esse o motivo para retomarem, em sua maioria, antecedentes com o traço [+gs]; ao passo que ONs (sendo categorias foneticamente nulas) não portam especificações de gênero, retomando antecedentes de traço [-gs]. Casos que contrariam a hipótese do gênero semântico, entendida aqui como a mais adequada para explicar o condicionamento de pronomes e objetos nulos, ainda devem ser detalhadamente estudados. 


\section{Referências}

AYRES, M. R. Aspectos condicionadores do objeto nulo e do pronome pleno em português brasileiro: uma análise da fala infantil. Dissertação de Mestrado, PUCRS, Porto Alegre, 2016.

AYRES, M. R.; OTHERO, G. A. Aspectos condicionadores do objeto nulo e do pronome pleno em português brasileiro: uma análise da fala infantil. Caderno de Squibs: Temas em estudos formais da linguagem, v. 2, n. 2, p. 1-12, 2016.

BAGNO, M. Gramática pedagógica do português brasileiro. São Paulo: Parábola, 2011.

BISOL, L.; MONARETTO, V. N. O. Prefácio: VARSUL e suas origens, uma história sumariada. ReVEL, edição especial n. 13, p. 6-11, 2016.

CASAGRANDE, S. A aquisição do objeto direto anafórico em português brasileiro. Dissertação de mestrado, UFSC, Florianópolis, 2007.

CASAGRANDE, S. Restrições de ocorrência do objeto direto anafórico no Português Brasileiro: gramática adulta e aquisição da linguagem. ReVEL, edição especial n. 6, p. 131163, 2012.

COLLISCHONN, G.; MONARETTO, V. Banco de dados VARSUL: a relevância de suas características e a abrangência de seus resultados. ALFA: Revista de Linguística, v. 56, n. 3, p. 835-853, 2012.

CREUS, S; MENUZZI, S. O papel do gênero na alternância entre objeto nulo e pronome pleno em português brasileiro. Revista da ABRALIN, Florianópolis, v. 3, n. 1-2, p. 149176, 2004.

194 CUNHA, C. de S. Indeterminação pronominal do sujeito. Dissertação de Mestrado. Faculdade de Letras/UFRJ, Rio de Janeiro, 1993.

CYRINO, S. M. O objeto nulo no português do Brasil: um estudo sintático-diacrônico. Tese de doutorado, UNICAMP, Campinas, 1994. (Publicada em 1997 pela Ed. da Universidade Estadual de Londrina, Londrina PR.)

CYRINO, S. M. Observações sobre a mudança diacrônica no português do Brasil: objeto nulo e clíticos. In: ROBERTS, I.; KATO, M. A. (Org.). Português brasileiro: uma viagem diacrônica. Campinas: Ed. da Unicamp, 1993. p. 163-184.

CYRINO, S. M. Para a história do português brasileiro: a presença do objeto nulo e a ausência dos clíticos. Letras de Hoje, v. 38, n. 1, p. 31-47, 2013.

DUARTE, M. E. Clítico acusativo, pronome lexical e categoria vazia no português do Brasil. In: TARALO, F. (Org.). Fotografia Sociolinguística. Campinas: Pontes/Ed. da UNICAMP, 1989. p. 19-34.

DUARTE, M. E. Do pronome nulo ao pronome pleno: a trajetória do sujeito no português do Brasil. In: ROBERTS, I.; KATO, M. A. (Org.). Português brasileiro: uma viagem diacrônica. Campinas: Ed. da Unicamp, 1993. p. 107-125. 
G. DE A.

OTHERO \& A.

C. SPINELli

Analisando

a retomada

anafórica do

objeto direto em português falado
LOREGIAN-PENKAL, L. Tu viu? Viste/Visse? A perda da morfologia verbal e o uso do pronome tu na região Sul. In: III Congresso Internacional de Dialetologia e Soiciolinguística. Londrina, 2014.

MONTEIRO, J. L. Pronomes pessoais: subsídios para uma gramática do português do Brasil. Fortaleza: Edições UFC, 1994.

OMENA, N. P. Pronome pessoal de terceira pessoa: suas formas variantes em função acusativa. Dissertação de Mestrado, PUC-RJ, Rio de Janeiro, 1978.

OTHERO, G. A.; AYRES, M. R.; SCHWANKE, C.; SPINELLI, A. C. A relevância do traço gênero semântico na realização do objeto nulo em português brasileiro. Working Papers em Linguística, v. 17, n. 1, p. 64-85, 2016.

OTHERO, G. A.; CARDOZO, R. W. A ordem pronominal em português brasileiro: da ênclise à próclise, do clítico ao tônico (or There and Back Again, a Word Order's Holiday). Fórum Linguístico, v. 14, n. 1, p. 1717-1734, 2017.

PERINI, M. A. Gramática descritiva do português brasileiro. Petrópolis: Vozes, 2016.

PINTO, C. A. V.; COELHO, I. L. O objeto direto anafórico de SN: uma análise da fala de Florianópolis em duas sincronias. ReVEL, edição especial n. 12, p. 245263, 2016.

PIVETTA, V. Objeto direto anafórico no português brasileiro: uma discussão sobre a importância dos traços semântico-pragmáticos - animacidade/especificidade vs. gênero semântico. Dissertação de mestrado, UFRGS, Porto Alegre, 2015.

SCHWANKE, C. Retomadas anafóricas de objeto direto em português brasileiro escrito. Trabalho de Conclusão de Curso, UFRGS, Porto Alegre, 2016.

SCHWENTER, S. A. Null objects across South America. In: Selected proceedings of the 8th Hispanic Linguistics Symposium. Somerville: Cascadilla Press, 2006. p. 23-36.

SCHWENTER, S.; SILVA, G. Overt vs. null direct objects in spoken Brazilian Portuguese: a semantic/pragmatic account. HISPANIA v. 85 n. 3, p. 577-586, 2002.

SCHWENTER, S. A.; SILVA, G. Anaphoric direct objects in spoken Brazilian Portuguese: semantics and pragmatics. Revista Internacional de Lingüística Iberoamericana, v. 1, n. 2, p. 99-123, 2003.

TARALlO, F. Relativization Strategies in Brazilian Portuguese. Tese de Doutorado, Univ. of Pennsylvania, Philadelphia, 1983.

VIEIRA-PINTO, C. A.; COELHO, I. L. O objeto direto anafórico de SN: uma análise da fala de Florianópolis em duas sincronias. ReVEL, edição especial n. 13, p. 245-263, 2016.

Submetido em: 30-01-2017

Aceito em: 15-05-2017
Revista Letras,

Curitiba, UFPR, n. 96, pp.174-195, jul./dez. 2017. ISSN 2236-0999 (versão eletrônica) 